\title{
Fatigue, Depression and Sleep Disturbance among Hemodialysis Patients
}

\author{
Hanaa Hamdy Ali ${ }^{1}$, Nadia Mohamed Taha ${ }^{2}$ \\ ${ }^{I}$ (lecturer-Psychiatric and Mental Health Nursing Department- Faculty of Nursing, Egypt) \\ ${ }^{2}$ (Assistant Professor of Medical Surgery Nursing Department- Faculty of Nursing Zagazig University, Egypt)
}

\begin{abstract}
:
Background: Patients on hemodialysis (HD) may experience troubling symptoms, which cause daily distress and negatively affects their quality of life (QOL).

Aim of the study: was to assess the psychological problems such as fatigue, depression and sleep disturbance among HD patients.

Design: This descriptive cross-sectional design was utilized to conduct this study.

Setting: The study was conducted in the HD units at the General and Fevers Hospitals in Zagazig City

Sample: A purposive sample of on 105 adult patients on HD who fulfilled the study inclusion criteria.

Tools: Four tools were used in the present study; the first tool was an interview form, the second tool was a Sleep Disturbance Scale, the third tool was Beck Depression Inventory Scale, and the fourth tools the Fatigue Severity Scale (FSS) of sleep disorder.

Results: The results revealed The study findings revealed that more than half of the patients were male (54.3\%), age 50 years or older (50.5\%), illiterate (57.1\%), and working (54.3\%). Overall, $90.5 \%$ of the patients had sleep problems and $83.8 \%$ had fatigue symptoms; $37.1 \%$ and $33.3 \%$ had severe and moderate depression symptoms respectively.

Conclusion: Patient's age, income, marital status, and duration of illness have significant influences on these disorders.

Recommendations: These patients need psychological support in order to relieve these symptoms and prevent their untoward effects on their health and wellbeing. Further research is proposed to test the effectiveness of nursing interventions in decreasing depression and fatigue symptoms, and improving the quality of sleep among HD patients.
\end{abstract}

Keywords: Hemodialysis, Depression, Fatigue, Sleep disorders

\section{Introduction}

Chronic kidney disease (CKD) is often unpredictable and patients may not feel ill as the disease progresses to end stage renal disease (ESRD), and requires dialysis or kidney transplant. Loss of kidney function occurs slowly, with the kidneys initially adapting well to the underlying causes of kidney damage (Castner, 2010). Many complications, such as anemia and bone disease, become evident as CKD progresses (National Kidney Foundation $[\mathbf{N K F}], 2011$ ). Eventually, Hemodialysis (HD) or Peritoneal Dialysis (PD) must be initiated in most patients (Lee et al., 2009a). Patients on HD account for approximately $92 \%$ of the overall dialysis population (United States Renal Data System [USRDS], 2012).

Fatigue is the inability of sustaining an effort either mentally or physically or both while signs and symptoms may be interconnected in a way not always clearly defined (Sakkas and Karatzaferi, 2012). It is one of the most common symptoms that patients with chronic illness experience (Kirshbaum, 2012), with a prevalence ranging from $60 \%$ to $97 \%$ (Griva et al., 2011). Yet, it is under-recognized and under-treated by providers, most likely due to its insidious, invisible nature (Ahlberg et al., 2005). Further, these patients report mental fatigue in the form of difficulty remembering names and participating in conversations (Horigan et al., 2013). Fatigue in patients on hemodialysis has been associated with lower quality of life (QoL) and lower survival rates (Horigan et al., 2013).

Depression is common in patients with ESRD, although its true prevalence among them is unknown. Estimates vary between 0 and $100 \%$, depending on the assessment tool used in screening (Almeras and Argiles, 2009). Meanwhile, depression may alter adversely the medical outcome of patients with ESRD (Horigan et al., 2013). However, not all ESRD patients have depressive symptoms, suggesting that other factors can also contribute to the development of this disease (Zyoud et al., 2010).

Sleep effectiveness is essential, although it varies duration among individuals (Al-Ameedy, 2014). Sleep complaints and disorders are common in patients with ESRD; 80\% of hemodialysis patients suffer from sleep abnormalities and the prevalence is higher than that in the general population (Gul et al., 2006). Research in Egypt revealed that 79\% of HD patients had sleep disorder (Sabry et al, 2010), while 78\% suffered from 
fatigue (Mohamed, 2013). In another study in Egypt, insomnia was prevalent among 69\% of HD patients (Ezzat and Mohab, 2015). Meanwhile, insomnia is associated with worse QoL in older adults (Abd Allah et al., 2014).

Nurses are directly responsible for patients undergoing HD and they administer care to reduce the complications (Adib-hajbagheri et al., 2014). The ESRD patients often feel helpless in dealing with their disease. These persistent stressors can lead to psychological problems such as depression and anxiety, which are common in ESRD patients receiving chronic HD (HD) (Demir et al., 2010). Nursing interventions have a great impact on reducing risk for complications and potential to promote health of end-stage-renal disease patients

(Abed Elsatar and Elhefnawy, 2013).

Significance of the study:

Evidence is emerging that cognitive impairment, depression and sleep disorders are very common in patients with ESRD, and this negatively affect their outcomes as well as their QOL. However, there is a paucity of research in this area in our community of patients. Since the psychiatric nurse has a pivotal role in caring and supporting those patients, it was deemed necessary to evaluate fatigue, depression and sleep disturbance among HD patients. This study aim was to assess the psychological problems such as fatigue, depression and sleep disturbance among hemodialysis (HD) patients.

Aim of the study:

The aim of this study was to assess the psychological problems such as fatigue, depression and sleep disturbance among HD patients.

Research question:

Are the patients on hemodialysis having psychological problems such as fatigue, depression and sleep disturbance?

\section{Subjects And Methods}

\subsection{Research Design:-}

This descriptive cross-sectional design will be utilized in this study

\subsection{Study Setting:-}

The study was conducted in the hemodialysis units at the General and Fevers Hospitals in Zagazig City. 2.3. Subjects:-

All adult patients regularly attending the study settings for hemodialysis during the time of the study for at least three months were included. The patients with concomitant diseases that prevent cooperation and those with history of psychiatric disease were excluded.

Sampling technique: Comprehensive sampling technique was used in the recruitment of this study subjects from the above mentioned setting and who fulfilled the study inclusion criteria.

Sample size calculation: all patients including adult age 18-65 in hemodialysis units in General and Fevers in Zagazig City

\subsection{Tools for data collection:-}

\section{Tool I: An interview questionnaire sheet}

This tool was used for data collection. It comprised a section for patient socio-demographic characteristics and medical history such as the duration of the disease and the period of HD.

\section{Tool II: The Sleep Disturbance Scale}

This tool was constructed by (Al Desoky, 2006). It has 40 statements checked as either "applies to me" or "does not apply to me." They are categorized into four categories: 1) sleep disturbance such as "I suffer from sleep apnea," 2) daytime functioning problems: such as: "I have problems at work because of sleepiness," 3) inefficient sleep such as: "I feel a headache when I wake up in the morning," and 4) sleep latency such as "I have difficulty entering into sleep." A statement checked as "applies to me" was scored 1 point and that checked "does not apply to me" was scored 0 point. The scores of each category and of the whole scale were summed up and converted into percent scores. A higher score meant the presence of sleep problems. A patient with a score of $60 \%$ or higher in a category or in the total scale was considered as suffering from the related sleep problem.

Tool III: Beck Depression Inventory (BDI) Scale:

This tool was originally constructed by (Aron, 1988). This standardized tool consists of 21 statements about feelings of failure, self-blame, guilt, etc., with four possible answer choices in increasing intensity scored from 0 to 3 points. A total score is obtained by summing up the scores of the 21 statements. It is then categorized according to the tool guidelines into normal (BDI >10), mild (BDI 11-20), moderate (BDI 21-30), and severe (BDI <30).

Tool IV: Fatigue Severity Scale (FSS)

This tool constructed by (Lauren, 1989). It has 9 statements rating the severity of fatigue such as "I am tired easily," and "Fatigue causes problems to me." The responses are on a numeric continuous 7-point scale from "disagree" to "agree." For each statement, a low score "1" indicates strong disagreement whereas a high score 
" 7 " indicates strong agreement and consequently more fatigue problem. The responses are scored accordingly from 1 to 7 points assigned to each answer. A total score of 36 or higher indicates fatigue.

\subsection{Preparatory phase:-}

A review of part and current available literature relevant to the problem and theoretical knowledge of the various aspect of the problem using books, articles, periodicals and magazines in order to get a clear picture of all aspects related to the problem of the research as well as to develop the study tools for data collection for the questionnaires of the memory pattern achievement motivation , meaning of life and performan

2.6. Content validity:-

A panel of five three experts in psychiatric health nurse will review the tools for clarity, relevance, comprehensive, understanding and applicability

\subsection{Content reliability:-}

Internal consistency reliability was done using Cronbach's Alpha to assess the consistency of results across items within a test. The reliability of the scales used in the tool was assessed in the pilot through measuring their internal consistency. They turned to be of high degrees of reliability with Cronbach alpha coefficients for Beck scale (0.807), Sleep scale (0.764), and Fatigue scale (0.983).

\subsection{Pilot study:-}

A pilot study will carried out on $10 \%$ from patients the selected criteria and will excluded later from the study sample, The purpose of the pilot study will tested the clarity of the tools and the different items of the tools and any necessary modification will be done when obtaining the required information results of the pilot study will helped to make such modification of the tools then will be revised redesign and the final forms of the tools will be obtained

\subsection{Fieldwork:-}

After securing official approvals, the researcher visited the study settings and met with the nursing director of each hospital to determine the suitable time to collect the data. The researcher then started recruiting the patients according to eligibility criteria. She met individually with each, explained to him/her the aim and procedures of the study, and invited him/her to participate. The patients who gave their consent to participate were interviewed using the data collection tool. Each interview took 25-30 minutes. It was done individually, ensuring complete patient privacy. The work was done six days per week, and lasted from February to July 2015.

\subsection{Ethical Considerations:-}

Patients will be interviewed in general and Fevers Hospital in Zagazig City using self-rating scale to ensuring privacy and each participant has complete freedom to be withdrawing at any time from the study, total confidentiality and anonymity of any information will be ensured, professional help will be provided to patients

\subsection{Administrative Design:-}

An official permission will be obtained using proper channels of communication .prior to an informed consent will be obtained from the directors of General and Fevers Hospitals in Zagazig city in which the study will be conducted.

\subsection{Statistical Design:-}

Data entry and statistical analysis were done using SPSS 20.0 statistical software package. Cronbach alpha coefficient was calculated to assess the reliability of the developed tools through their internal consistency. Spearman rank correlation was used for assessment of the inter-relationships among quantitative variables and ranked ones. In order to identify the independent predictors of sleep, fatigue and depression scores, multiple linear regression analysis was used. Statistical significance was considered at $\mathrm{p}$-value $<0.05$.

\section{Results}

The study sample included slightly more male patients (54.3\%), with age 50 years or older $(50.5 \%)$ as shown in Table 1. Slightly more than half of them were illiterate (57.1\%), while less than half were not working (45.7\%). The majority were married (75.2\%), had children (95.8\%), and had sufficient income (71.4\%). As regards the disease characteristics of the patients in the study sample, Table 2 demonstrates that the duration of the renal disease ranged between $<1$ and 15 years, with median 3 years. As for the duration of hemodialysis, the median was also 3 years.

Table 2 shows that the highest types of sleep problems reported by the patients in the study sample were related to sleep disturbance $(85.7 \%)$ and sleep insufficiency $(85.7 \%)$. Conversely, the lowest type was that of daytime functioning problems $(77.1 \%)$. In total, the great majority of the patients in the study sample $(90.5 \%)$ had sleep problems. Concerning the fatigue symptoms reported by the patients in the study sample,

Table 3 demonstrates that the most common symptoms were those of "Exercise brings me fatigue" (92.4\%), "Fatigue prevents me from carrying out my practical, family and social duties" $(89.5 \%)$, and "I am tired easily" $(88,6 \%)$. At the other end, the least reported symptom was that of "Motivation decreases when I am tired or fatigued" $(82.9 \%)$. In total, the majority of the patients in the study sample $(83.8 \%)$ had total fatigue symptoms. 
As regards depression, the table illustrates that slightly more than third of the patients in the study sample had severe depression symptoms (37.1\%). An additional third had moderate depression symptoms (33.3\%), while only $12.4 \%$ had no such symptoms.

Table 4 demonstrates the absence of any correlation of statistical significance among patients' scores of depression, sleep, and fatigue. As regards the correlations between patients' scores of depression, sleep, and fatigue and their personal and disease characteristics, the table indicates that the only correlation of statistical significance was between patients' scores of depression and their level of education. This correlation is weak and negative $(\mathrm{r}=-0.217)$.

Table 5 shows statistically significant weak positive correlations between patients' score of depression symptoms and their problems of sleep disturbance $(r=0.204)$, and daytime sleep $(r=0.192)$. It also indicates the presence of a statistically significant weak positive correlation between patients' score of fatigue and their problems of sleep latency $(\mathrm{r}=0.225)$. In multivariate analysis (Table 6), the only statistically significant independent positive predictor of the depression symptoms score was being married. On the other hand, being treated in a general hospital, having sufficient income, and the duration of illness were negative predictors. The model explains $17 \%$ of the variation in the depression score. None of the other patients' socio-demographic or disease characteristics had a statistically significant relation with their depression symptoms. As regards the best fitting regression model for the sleep problems score, the table indicates that the statistically significant independent positive predictors were being treated in the fevers hospital, longer duration of illness, and higher depression symptoms score. The model explains $26 \%$ of the variation in the sleep problems score. None of the other patients' socio-demographic or disease characteristics had a statistically significant relation with their sleep score. For the fatigue score, the same table demonstrates that the statistically significant independent positive predictors were being treated in the fevers hospital, as well as older age, while a sufficient income was a negative predictor. The model explains $11 \%$ of the variation in the fatigue score. None of the other patients' socio-demographic or disease characteristics had a statistically significant relation with their sleep score.

Table 1: Socio-demographic and disease characteristics of patients in the study sample $(n=105)$

\begin{tabular}{|c|c|c|}
\hline & Frequency & Percent \\
\hline \multicolumn{3}{|l|}{ Gender: } \\
\hline Male & 57 & 54.3 \\
\hline Female & 48 & 45.7 \\
\hline \multicolumn{3}{|l|}{ Age: } \\
\hline $30-<50$ & 52 & 49.5 \\
\hline $50+$ & 53 & 50.5 \\
\hline \multicolumn{3}{|l|}{ Current marital status: } \\
\hline Unmarried & 26 & 24.8 \\
\hline Married & 79 & 75.2 \\
\hline \multicolumn{3}{|l|}{ Education: } \\
\hline Illiterate & 60 & 57.1 \\
\hline Basic/intermediate & 29 & 27.6 \\
\hline University & 16 & 15.2 \\
\hline \multicolumn{3}{|l|}{ Job: } \\
\hline Housewife/ Unemployed & 48 & 45.7 \\
\hline Farmer/worker & 33 & 31.4 \\
\hline Employee & 24 & 22.9 \\
\hline \multicolumn{3}{|l|}{ Income: } \\
\hline Sufficient & 75 & 71.4 \\
\hline Insufficient & 30 & 28.6 \\
\hline \multicolumn{3}{|l|}{ Have children: } \\
\hline No & 4 & 4.2 \\
\hline Yes & 91 & 95.8 \\
\hline \multicolumn{3}{|c|}{ Duration of illness (years): } \\
\hline$<5$ & 65 & 61.9 \\
\hline $5+$ & 40 & 38.1 \\
\hline Range & $<1.0-15.0$ & \\
\hline Mean \pm SD & $4.2 \pm 3.3$ & \\
\hline Median & 3.0 & \\
\hline \multicolumn{3}{|c|}{ Hemodialysis duration (years): } \\
\hline$<5$ & 64 & 61.0 \\
\hline $5+$ & 41 & 39.0 \\
\hline Range & $<1.0-15.0$ & \\
\hline Mean \pm SD & $4.3 \pm 3.2$ & \\
\hline Median & 3.0 & \\
\hline
\end{tabular}

Table 2: Sleep problems among patients in the study sample $(n=105)$

\begin{tabular}{|l|l|l|}
\hline Sleep problems & Frequency & Percent \\
\hline Sleep disturbance: & & \\
\hline Yes & 90 & 85.7 \\
\hline
\end{tabular}


Fatigue, Depression And Sleep Disturbance Among Hemodialysis Patients

\begin{tabular}{|l|l|l|}
\hline No & 15 & 14.3 \\
\hline Daytime functioning problems: & & \\
\hline Yes & 81 & 77.1 \\
\hline No & 24 & 22.9 \\
\hline Sleep inefficiency: & & \\
\hline Yes & 90 & 85.7 \\
\hline No & 15 & 14.3 \\
\hline Sleep latency: & & \\
\hline Yes & 86 & 81.9 \\
\hline No & 19 & 18.1 \\
\hline Total sleep problem: & & \\
\hline Yes & 95 & 90.5 \\
\hline No & 10 & 9.5 \\
\hline
\end{tabular}

Table 3: Fatigue and depression symptoms among patients in the study sample $(\mathrm{n}=105)$

\begin{tabular}{|l|l|l|}
\hline During the last week: & Frequency & Percent \\
\hline Motivation decreases when I am tired or fatigued & 87 & 82.9 \\
\hline Exercise brings me fatigue & 97 & 92.4 \\
\hline I am tired easily & 93 & 88.6 \\
\hline Fatigue prevents my physical functions & 92 & 87.6 \\
\hline Fatigue causes frequent problems for me & 89 & 84.8 \\
\hline My fatigue prevents continuation of my physical functions & 92 & 87.6 \\
\hline My fatigue prevents me from doing my duties and responsibilities & 89 & 84.8 \\
\hline Fatigue is one of three symptoms that most impede my activities & 92 & 87.6 \\
\hline Fatigue prevents me from carrying out my practical, family and social duties & 94 & 89.5 \\
\hline Total fatigue: & & \\
\hline Yes & 88 & 83.8 \\
\hline No & 17 & 16.2 \\
\hline Depression: & & \\
\hline None & 13 & 12.4 \\
\hline Mild & 18 & 17.1 \\
\hline Moderate & 35 & 33.3 \\
\hline Severe & 39 & 37.1 \\
\hline
\end{tabular}

Table 4: Correlation between depression, sleep, and fatigue scores and patients' characteristics $(n=105)$

(*) Statistically significant at $\mathrm{p}<0.05$

\begin{tabular}{|l|l|l|l|}
\hline \multirow{2}{*}{} & \multicolumn{3}{|l|}{$\begin{array}{l}\text { Spearman's rank correlation } \\
\text { coefficient }\end{array}$} \\
\cline { 2 - 4 } & Depression & Sleep & Fatigue \\
\hline Depression & & & \\
\hline Sleep & 0.19 & & \\
\hline Fatigue & 0.07 & 0.13 & \\
\hline Age & 0.05 & -0.07 & 0.08 \\
\hline Education & $-.217^{*}$ & -0.02 & -0.07 \\
\hline No. of child & -0.02 & -0.10 & 0.07 \\
\hline Duration of illness & -0.19 & 0.10 & -0.12 \\
\hline Duration of hemodialysis & 0.13 & -0.13 & 0.14 \\
\hline
\end{tabular}

Table 5: Correlation between depression and fatigue scores and sleep domains ( $\mathrm{n}=105)$

\begin{tabular}{|l|l|l|}
\hline Sleep domains scores & Spearman's rank correlation coefficient \\
\cline { 2 - 3 } & Depression & Fatigue \\
\hline Sleep disturbance & $.204^{*}$ & 0.09 \\
\hline Daytime sleep & $.192^{*}$ & 0.03 \\
\hline Sleep efficiency & 0.12 & 0.17 \\
\hline Sleep latency & -0.02 & $.225^{*}$ \\
\hline
\end{tabular}

(*) Statistically significant at $\mathrm{p}<0.05$

Table 6: Best fitting multiple linear regression model for the depression, sleep, and fatigue scores $(\mathrm{n}=105)$

\begin{tabular}{|l|l|l|l|l|l|l|}
\hline \multirow{2}{*}{$\begin{array}{l}\text { Unstandardized } \\
\text { Coefficients }\end{array}$} & $\begin{array}{l}\text { Standardized } \\
\text { Coefficients }\end{array}$ & t-test & p-value & $\begin{array}{l}\text { 95\% Confidence } \\
\text { Interval for B }\end{array}$ \\
\cline { 6 - 7 } & B & Std. Error & & Lower & Upper \\
\hline
\end{tabular}


Fatigue, Depression And Sleep Disturbance Among Hemodialysis Patients

\begin{tabular}{|c|c|c|c|c|c|c|c|}
\hline \multicolumn{8}{|l|}{ Depression score } \\
\hline Constant & 27.99 & 3.40 & & 8.229 & $<0.001$ & 21.24 & 34.74 \\
\hline General Hospital & -2.23 & 1.10 & -0.19 & 2.022 & 0.046 & -4.42 & -0.04 \\
\hline Married & 2.68 & 1.11 & 0.22 & 2.420 & 0.017 & 0.48 & 4.87 \\
\hline Sufficient income & -5.78 & 1.92 & $\begin{array}{c}-0.27 \\
\end{array}$ & 3.009 & 0.003 & $\begin{array}{l}-9.59 \\
\end{array}$ & -1.97 \\
\hline Duration of illness & -0.57 & 0.26 & -0.20 & 2.148 & 0.034 & -1.09 & -0.04 \\
\hline \multicolumn{8}{|c|}{$\begin{array}{lc}\text { Model ANOVA: } \mathrm{F}=6.13, \mathrm{p}<0.001 & \mathrm{r} \text {-square }=0.17 \\
\text { Variables entered and excluded: age, gender, education, job status, duration of dialysis }\end{array}$} \\
\hline \multicolumn{8}{|l|}{ Sleep score } \\
\hline Constant & 13.87 & 2.60 & & 5.338 & $<0.001$ & 8.71 & 19.02 \\
\hline Fevers Hospital & 3.70 & 0.73 & 0.45 & 5.080 & $<0.001$ & 2.25 & 5.14 \\
\hline Duration of illness & 0.51 & 0.17 & 0.25 & 2.907 & 0.004 & 0.16 & 0.85 \\
\hline Depression score & 0.26 & 0.06 & 0.38 & 4.307 & $<0.001$ & 0.14 & 0.38 \\
\hline \multicolumn{8}{|c|}{$\begin{array}{l}\text { Model ANOVA: } \mathrm{F}=12.954, \mathrm{p}<0.001 \\
\text { Variables entered and excluded: age, gender, marital status, education, job status, income, duration of dialysis }\end{array}$} \\
\hline \multicolumn{8}{|c|}{ Fatigue score } \\
\hline Constant & 5.12 & 0.43 & & 11.991 & $<0.001$ & 4.27 & 5.96 \\
\hline Fevers hospital & 0.28 & 0.11 & 0.23 & 2.517 & 0.013 & 0.06 & 0.49 \\
\hline Age & 0.24 & 0.12 & 0.19 & 2.025 & 0.046 & 0.00 & 0.47 \\
\hline Sufficient income & -0.55 & 0.20 & -0.27 & -2.786 & 0.006 & -0.95 & -0.16 \\
\hline
\end{tabular}

\section{Discussion}

The quality of life of hemodialysis (HD) patients is hampered by disturbed sleep quality related to circadian clock performance (Russcher et al, 2015), in addition to depression considered as one of the most common comorbidities in these patients (Wang et al, 2015). This study aim was to assess the psychological problems such as fatigue, depression and sleep disturbance among hemodialysis (HD) patients. The findings indicate that the majority of these patients actually suffer moderate to severe degrees of depressive symptoms, in addition to fatigue and sleep disorders. These would certainly jeopardize their wellbeing and quality of life. The duration of the renal disease was variable in the present study sample, with a wide range of almost 15 years. This was intended to be able to study the effect of the duration of illness on the symptoms of depression and fatigue, and on sleep problems. In fact, the findings revealed the duration of illness as an independent positive predictor of the depression symptoms score. This means that the depression score increases with longer duration of renal disease, which is in congruence with the findings of Bossola et al (2014) in Italy. Our study also involved patients on HD for at least three months. This period was set as an inclusion criterion to avoid the early psychological problems that these patients may experience at the start of HD, with the fears from the place and machinery. Similar fears and concerns were reported by Taylor et al (2016) among early HD patients in Australia. More than $90 \%$ of the patients in the present study had sleep problems. This very high prevalence rate indicates the urgent need to recognize such problems among these patients in order to help them having good efficient and quality sleep time. In line with this, a study in Iran (Masoumi et al, 2013) revealed that the prevalence of sleep problems among patients on maintenance HD was $86.6 \%$, which is quite close to our figure. Moreover, the main sleep problem identified among their patients was that related to sleep efficiency, which is similar to the results of our study. Meanwhile, a lower percentage of patients having sleep problems was reported in a study in Sweden (Yngman-Uhlin et al, 2012), as low as 65\% compared to more than $90 \%$ in the current study. This is probably due to more attention given to the diagnosis and management of sleep problems in their setting. Concerning the predictors of sleep problems, the present study identified depression as an important factor significantly influencing them. Moreover, the patients with more sleep disturbance, daytime functioning problems, and sleep inefficiency had more severe depression symptoms. The findings are in agreement with the results of a study carried out in Serbia on patients on maintenance HD (Trbojevi $\square$ Stankovi $\square$ et al, 2014) This study demonstrated a significant positive correlation between patients' scores of depression and sleep problems. On the same line, Wang et al (2015), in a study in China identified depression as a significant indicator of sleep problems among patients on maintenance HD.

Another factor identified as a significant predictor of sleep problems among HD patients in the present study is the duration of renal disease. This is quite expected given the burden of the sessions on the patient, in addition to the stress and anxiety associated with the disease itself, as well as those of HD. In congruence with this, a number of studies in Egypt (El-Refaey et al, 2013), Korea (Kang et al, 2015), Iran (Chavoshi et al, 2015), and Serbia (Trbojevi $\square$-Stankovi $\square$ et al, 2014) demonstrated significant relations between the prevalence of sleep problems among patients on maintenance HD and the duration of illness and of hemodialysis.

The present study has revealed a high prevalence of depressive symptoms among the patients on HD. The findings indicate that depression is a major problem among these patients, which is quite understandable since these patients know that they would continue on this management regimen, with all its burdens, for life. 
Added to this are the dietary and other daily life restrictions. In congruence with this, Rahimipour et al (2015), in Iran, mentioned that renal failure patients experience high levels of depression due to psychological tension. Nonetheless, the percentages of patients having depression symptoms in the present study are higher compared to those reported in a systematic review carried out by Ma and Li (2016) in Hong Kong, where depression ranged between $22.8 \%$ and $39.3 \%$. The authors attributed the variations in the results of various studies to the use of different tools in the diagnosis of depression, in addition to patient's medical and health status, particularly the levels of blood urea and creatinine, which have a negative impact on depression symptoms.

In multivariate analysis, the independent positive predictors of the depression symptoms score among the patients in the current study were the married status, and income. The finding that depression is more prevalent among the married patients compared with the unmarried might be explained by the fact that a married patient may feel more responsibility towards his/her family, financially, physically, and psychologically. The feeling of inability to fulfill these roles and responsibilities would certainly worsen the depression symptoms. In agreement with this, Al Zaben et al (2014), in a study in Saudi Arabia, reported that being married was significantly associated with depression symptoms among chronic renal patients on HD. Moreover, the present study identified a shorter duration of illness/HD as an independent positive predictor of the depression score. This might indicate the effect of the new procedure and regimen of management on these patients, compared to those with longer durations who may have adapted to this. In agreement with this finding, $\mathbf{H u}$ et al (2015), in a recent study in China, identified a shorter duration of HD as a significant independent predictor of depression symptoms among HD patients.

The current study has also demonstrated that a great majority of the patients on HD had fatigue symptoms. The most commonly reported complaints were related to inability to perform family and social tasks, with easy tiredness, and consequent lower motivation. In agreement with this, Biniaz et al (2013), in a study in Iran, reported that all studied patients on HD had fatigue symptoms. Moreover, a study in Greece demonstrated that approximately two-thirds of the studied patients on maintenance HD were having moderate to severe degrees of fatigue (Zyga et al, 2015). The high prevalence of fatigue would certainly have a negative impact on the quality of life of patients on HD. It was even associated with a higher risk of mortality in an Italian study (Bossola et al, 2015). Hence, the fatigue problem deserves more attention in its diagnosis and management in patients on HD.

The multivariate analysis in the current study identified older age and lower income as independent significant positive predictors of fatigue score. The relation with age is quite plausible given the effects of aging on cardio-respiratory and musculoskeletal systems leading to less effort endurance. The effect of the income may be related to nutrition, since these patients need a balanced diet that poor ones cannot afford. In line with this, Jhamb et al (2011), in a study in the United States, found a significant association between fatigue and older patients' age. Similarly, a study in Taiwan demonstrated a significant association between fatigue and the state of nutrition of patients on maintenance HD (Wang et al, 2012).

The current study demonstrated significant associations between HD patients' fatigue symptoms and their sleep disturbance, daytime functioning problems, sleep inefficiency, and total sleep problems. Moreover, patients' score of fatigue and their problems of sleep latency were significantly and positively correlated. This might be explained by that the patients who do not get enough hours of efficient sleep are more susceptible to feel weakness and fatigue, and to get easily tired. In agreement with these findings, Lindner et al (2015), in a study in Hungary, reported that poor self-perceived sleep, with sleepiness, impaired daytime functioning in patients with chronic kidney disease is associated with fatigue.

Lastly, the hospital setting seems to be an important determinant of HD patients' fatigue and sleep disorders. Thus, the present study showed that being treated in one of the two study hospitals enhanced sleep problems treatment in the other one enhances fatigue symptoms. These differences might be attributed to the hemodialysis regimen itself such as the timing, duration, and frequency of the sessions. It might also be related to the type of care and attention given by the hospital staff and caregivers to these sleep and fatigue problems. Thus, Saeedi et al (2014), in Iran, showed that a caring hospital staff who train HD patients in sleep hygiene has a positive influence on HD patients' related disorders.

\section{Conclusion}

The study results make possible to conclude that the patients on HD have a very high prevalence of various types of sleep problems, depression symptoms, and fatigue. Patient's age, income, marital status, and duration of illness have significant influences on these disorders. Hence, these patients need psychological support to relieve these symptoms and prevent their untoward effects on their health.

\section{Recommendations}

In view of the study results, the following recommendations are proposed. the patients on HD must be periodically assessed for the presence or development of depression, fatigue or sleep 
problems using simple scales as those used in the present study by the psychiatric or HD nurse. The psychiatric nurse should provide HD patients with information regarding healthy sleep habits, and train them in relaxation techniques. Special care should be provided to older patients, with no education and with insufficient income, and those with long duration of HD or renal disease. Further research is proposed to test the effectiveness of nursing interventions in decreasing depression and fatigue symptoms, and improving the quality of sleep among HD patients.

\section{References}

[1]. Abd Allah E.S., Abdel-Aziz H.R., and Abo El-Seoud A.R. (2014): Insomnia: Prevalence, risk factors, and its effect on quality of life among elderly in Zagazig City, Egypt. Journal of Nursing Education and Practice; 4(8).

[2]. Abed Elsatar O.M.A., and Elhefnawy K.A. (2013): Patient-Care Practices Associated with Increased Transmission of Hepatitis C Virus Infection among Hemodialysis patients. J Am Sci; 9(3):389- 396

[3]. Adib-hajbagheri M., Molavizadeh N., Alavi N.M., and Abadi M.H.M. (2014): Factors associated with complications of vascular access site in hemodialysis patients in Isfahan Aliasghar hospital. Iranian Journal of Nursing and Midwifery Research; 19(2): 208214.

[4]. Ahlberg K., Ekman T., and Gaston-Johansson F. (2005): The experience of fatigue, other symptoms, and global quality of life during radiotherapy for uterine cancer. International Journal of Nursing Studies.;42:377-386.

[5]. $\quad$ Al-Desoky M. (2006): Disturbance .htt;//adf.ly /kowwd. health psychologist an 12-882013

[6]. Al Zaben F., Khalifa D.A., Sehlo M.G., Al Shohaib S., Shaheen F., Alhozali H., Hariri A.O., Ahmad R.G., Kabli M.R., and Koenig H.G. (2014): Depression in patients with chronic kidney disease on dialysis in Saudi Arabia. Int Urol Nephrol.;46(12):2393-402. doi: 10.1007/s11255-014-0802-2. Epub 2014 Aug 28.

[7]. Al-Ameedy W.A. (2014): Insomnia in Patients with Renal Failure Undergoing Hemodialysis. Medical Journal of Babylon; 10:3.

[8]. Almeras C., and Argiles A. (2009): The general picture of uremia. Seminars in Dialysis.; 22(4):329-333.

[9]. Aron T. (1988): htt;//www,ilajj.com/2013/10/test-Beck-Aaron-depression-pdf-doc-html//sthash.gobxw97y.d.puf

[10]. Biniaz V., Tayybi A., Nemati E., Sadeghi Shermeh M., and Ebadi A. (2013): Different aspects of fatigue experienced by patients receiving maintenance dialysis in hemodialysis units. Nephrourol Mon.;5(4):897-900. doi: 10.5812/numonthly. 11667. Epub 2013 Aug 20

[11]. Bossola M., Di Stasio E., Antocicco M., Panico L., Pepe G., and Tazza L. (2015): Fatigue Is Associated with Increased Risk of Mortality in Patients on Chronic Hemodialysis. Nephron.; 130(2):113-8. doi: 10.1159/000430827. Epub 2015 May 27.

[12]. Bossola M., Di Stasio E., Giungi S., Rosa F., and Tazza L. (2014): Fatigue is associated with serum interleukin-6 levels and symptoms of depression in patients on chronichemodialysis. J Pain Symptom Manage. 2015 Mar;49(3):578-85. doi: 10.1016/j.jpainsymman.2014.07.009. Epub 2014 Aug 15.

[13]. Castner D. (2010): Understanding the stages of chronic kidney disease. Nursing. ;40(5):24-31.

[14]. Chavoshi F., Einollahi B., Sadeghniat Haghighi K., Saraei M., and Izadianmehr N. (2015): Prevalence and sleep related disorders of restless leg syndrome in hemodialysis patients. Nephrourol Mon.;7(2):e24611. doi: 10.5812/numonthly.24611. eCollection 2015 Mar.

[15]. Demir S., Tufan G., and Erem O. (2010): Sociotropic or autonomous personality and problem solving in peritoneal dialysis patients. J Int Med Res;38:1491-6.

[16]. El-Refaey A.M., Elsayed R.M., Sarhan A., Bakr A., Hammad A., Elmougy A., and Aboelyazeed A.Y. (2013): Sleep quality assessment using polysomnography in children on regular hemodialysis. Saudi J Kidney Dis Transpl.;24(4):714-8.

[17]. Ezzat H., and Mohab A. (2015): Prevalence of sleep disorders among ESRD patients. Ren Fail.;37(6):1013-9. doi: 10.3109/0886022X.2015.1044401. Epub 2015 May 11

[18]. Griva K., Mooppil N., Seet P., Krishnan D.S., James H., and Newman S.P. (2011): The NKF-NUS hemodialysis trial protocol - a randomized controlled trial to determine the effectiveness of a self management intervention for hemodialysis patients. BMC Nephrol.;12:4

[19]. Gul A., Aoun N., and Trayner E.M. (2006): Jr Why do patients sleep on dialysis? Seminars in dialysis.; 19(2):152-157.

[20]. Horigan A.E., Schneider S.M., Docherty S., Barroso J. (2013): The Experience and Self-Management of Fatigue in Hemodialysis Patients. Nephrology Nursing Journal of the American Nephrology Nurses’ Association.;40(2):113-123.

[21]. Hu A., Xue Z., Mwansisya T.E., Zhou A., Pu W., Chen X., Sun M., Wang P., Fan H., Wang Z., Ouyang X., Liu Z., and Rosenheck R. (2015): Major depressive disorder in hemodialysis patients in China. Asia Pac Psychiatry.;7(1):78-84. doi: 10.1111/appy.12110. Epub 2013 Nov 21.

[22]. Jhamb M., Pike F., Ramer S., Argyropoulos C., Steel J., Dew M.A., Weisbord S.D., Weissfeld L., and Unruh M. (2011): Impact of fatigue on outcomes in the hemodialysis (HEMO) study. Am. J. Nephrol.; 33: 515-523.

[23]. Kang G.W., Lee I.H., Ahn K.S., Lee J., Ji Y., and Woo J. (2015): Clinical and psychosocial factors predicting health-related quality of life in hemodialysis patients. Hemodial Int.;19(3):439-46. doi: 10.1111/hdi.12271. Epub 2015 Feb 3.

[24]. Kirshbaum M. (2012): Waking up to fatigue. British Journal of Community Nursing.;17(2):49.

[25]. Lauren B.K. (1989): fatigue severity scale (FSS) of sleep disorders .health women.1-877.986-9472(tall-free) on the web at www .health women .org

[26]. Lee, Lin, Chaboyer, Chiang, Hung (2007a): The fatigue experience of haemodialysis patients in Taiwan. Journal of Clinical Nursing.;16(2):407-413.

[27]. Lindner A.V., Novak M., Bohra M., and Mucsi I. (2015): Insomnia in Patients With Chronic Kidney Disease. Semin Nephrol.; 35(4):359-72. doi: 0.1016/j.semnephrol.2015.06.007.

[28]. Ma T.K., and Li P.K. (2016): Depression in dialysis patients. Nephrology (Carlton). 2016 Feb 10. doi: 10.1111/nep.12742. [Epub ahead of print]

[29]. Masoumi M., Naini A.E., Aghaghazvini R., Amra B., and Gholamrezaei A. (2013): Sleep quality in patients on maintenance hemodialysis and peritoneal dialysis. Int J Prev Med.;4(2):165-72.

[30]. Mohamed A.A. (2013): palliative care planning for the most common problems for patients for patients undergoing hemodialysis at hodiedah Dialysis ; unpublished doctorate of thesis Faculty of nursing, Zagazic of Nursing, pp. 110-111.

[31]. National Kidney Foundation [NKF], (2011): About chronic kidney disease. 2011 Retrieved from http://www.kidney.org /kidneydisease/ckd/index.cfm\#whatare.

[32]. Rahimipour M., Shahgholian N., and Yazdani M. (2015): Effect of hope therapy on depression, anxiety, and stress among the patients undergoing hemodialysis. Iran J Nurs Midwifery Res.;20(6):694-9. doi: 10.4103/1735-9066.170007. 
[33]. Russcher M., Chaves I., Lech K., Koch B.C., Nagtegaal J.E., Dorsman K.F., Jong A., Kayser M., van Faassen H.M., Kema I.P., van der Horst G.T., and Gaillard C.A. (2015): An observational study on disturbed peripheral circadian rhythms in hemodialysis patients. Chronobiol Int.;32(6):848-57. doi: 10.3109/07420528.2015.1048868. Epub 2015 Jun 23.

[34]. Sabry A.A., Abo-Zenah H., Wafa E., Mahmoud K., El-Dahshan K., Hassan A., Abbas T.M., Saleh Ael-B., and Okasha K. (2010): Sleep disorders in hemodialysis patients. Saudi J Kidney Dis Transpl.;21(2):300-5.

[35]. Saeedi M., Shamsikhani S., Varvani Farahani P., and Haghverdi F. (2014): Sleep hygiene training program for patients on hemodialysis. Iran J Kidney Dis.;8(1):65-9.

[36]. Sakkas G.K., and Karatzaferi C. (2012): Hemodialysis fatigue: just "simple" fatigue or a syndrome on its own right? Front Physiol.; 3:306.

[37]. Taylor M.J., Hanson C.S., Casey JR., Craig J.C., Harris D., Tong A. (2016): "You know your own fistula, it becomes a part of you"Patient perspectives on vascular access: A semistructured interview study. Hemodial Int.;20(1):5-14. doi: 10.1111/hdi.12340. Epub 2015 Jul 22

[38]. Trbojević-Stanković Jasna, Biljana Stojimirović1,3, Zoran Bukumirić4 , Edvin Hadžibulić5 , Branislav Andrić6 , Verica Djordjević7 , Zoran Marjanović7 , Fatmir Birdjozlić5 , Dejan Nešić8, Dijana Jovanović1,3 Depression and Quality of Sleep in Maintenance Hemodialysis Patients. Srp Arh Celok Lek. 2014 Jul-Aug;142(7-8):437-443 DOI: 10.2298/SARH1408437T

[39]. United States Renal Data System [USRDS], (2012): United States Renal Data System 2012 annual data report: Atlas of chronic kidney disease and end-stage renal disease in the United States. Bethesda, MD: National Institutes of Health, National Institute of Diabetes and Digestive and Kidney Diseases.

[40]. Wang L.J., Wu M.S., Hsu H.J., Wu I.W., Sun C.Y., Chou C.C., Lee C.C., Tsai C.R., Tsai Y.C., and Chen C.K. (2012): The relationship between psychological factors, inflammation, and nutrition in patients with chronic renal failure undergoing hemodialysis. Int J Psychiatry Med.;44(2):105-18.

[41]. Wang S.Y., Zang X.Y., Liu J.D., Cheng M., Shi Y.X., and Zhao Y. (2015): Indicators and correlates of psychological disturbance in Chinese patients receiving maintenance hemodialysis: a cross-sectional study. Int Urol Nephrol.;47(4):679-89. doi: 10.1007/s11255-015-0910-7. Epub 2015 Jan 28.

[42]. Yngman-Uhlin P., Fernstrom A., BorjesonS., and Edell-Gustafsson U.( 2012): Evaluation of an individual sleep intervention programme in people undergoing peritoneal dialysis treatment. J ClinNurs. 21:3402-3417.

[43]. Zyga S., Alikari V., Sachlas A., Fradelos E.C., Stathoulis J., Panoutsopoulos G., Georgopoulou M., Theophilou P., and Lavdaniti M. (2015): Assessment of Fatigue in End Stage Renal Disease Patients Undergoing Hemodialysis: Prevalence and Associated Factors. Med Arch.;69(6):376-80. doi: 10.5455/medarh.2015.69.376-380.

[44]. Zyoud S.H., Awang R., Syed Sulaiman S.A., and Al-jabi S.W. (2010): High prevalence of hypokalemia after acute acetaminophen overdose: Impact of psychiatric illness. Hum. Exp. Toxicol.; 29: 773-778. 